\title{
Avaliação do processo de ensino e aprendizagem para além dos muros da hierarquia escolar
}

Jéssica Gonçalves ${ }^{1}$

\begin{abstract}
Resumo
O objetivo deste texto é analisar a forma como a avaliação está posta atualmente no processo de ensino e aprendizagem como um instrumento de controle, baseado em exames, que contribui para consolidar não apenas uma classificação dos alunos no interior da escola, mas também um efeito social de hierarquia. A partir do modelo tradicional do processo de ensino e aprendizagem, baseado na técnica da prelação do conteúdo pelo professor (agente ativo que detém o conhecimento) e a demonstração pelos alunos da apropriação do conteúdo (agente passivo que apenas recepciona as informações), a avaliação torna-se o instrumento legitimador da mencionada prática. Pautada somente em exames, a avaliação do processo de ensino e aprendizagem fica restrita ao modo de atestar e controlar quais alunos estão aptos a prosseguir às demais fases, destoando-se das suas demais funções primordiais de cunho pedagógico e diagnóstico.
\end{abstract}

\section{Palavras-chave}

Processo de Ensino e Aprendizagem. Avaliação. Exame. Hierarquia Social.

1. Mestranda em Direito na Universidade Federal de Santa Catarina. E-mail: jessic.goncalves@hotmail.com. 


\title{
The evaluation of teaching and learning process beyond the walls of school hierarchy
}

Jéssica Gonçalves*

\begin{abstract}
This paper aims to analyze how the evaluation is currently placed in the teaching and learning process as an instrument of control, based on tests, that contributes to consolidate not only a classification of students in the school, but also a social hierarchy effect. Because of the traditional standard of the teaching and learning process which based on the possession of knowledge by the teacher (the active agent who gives information) and the demonstration by the students of the learning (passive agent who only receives information), the evaluation becomes the legitimizing instrument of that practice. Based only in tests, the evaluation of the teaching and learning process is limited to certify and control the students that are able to continue to the other phases, which is contradictory to its other mainly functions, pedagogic and diagnostic
\end{abstract}

\section{Keywords}

Teaching and Learning Process. Evaluation. Exam. Social Hierarchy.

\footnotetext{
* MSc Student in Law, Federal University of Santa Catarina; State of Santa Catarina, Brazil. E-mail: jessic.
} goncalves@hotmail.com. 


\section{Introdução}

O processo de ensino e aprendizagem encontra-se mergulhado historicamente em uma metodologia de transmissão do conhecimento pelo sujeito detentor do saber, denominado professor, e a tarefa de adquirir e memorizar o conteúdo por um sujeito passivo na relação, conhecido como aluno.

Partindo dessa pedagogia tradicional, em que se estabelecem metas em confronto com os resultados obtidos, surge a necessidade de contabilizar o grau de aprendizagem com o escopo de controlar quais alunos estarão aptos para as demais etapas do conhecimento. Disso, a avaliação atua como mecanismo legitimador das atividades educacionais, capaz de aferir qual aluno adquiriu o conhecimento e poderá continuar no ensino.

Em um processo pedagógico adequado, a avaliação deve compreender três funções básicas, quais sejam: didático-pedagógica, diagnóstica e controle. No entanto, a herança da pedagogia sistematizada nos séculos XVI e XVII construiu um modelo que limita a avaliação à função de controlar os alunos, especificamente, como espelho de exames.

Distante da perspectiva de dinamismo, a avaliação, uma vez confundida com o ato de examinar, é dotada de atributos como pontualidade, seleção e exclusão. Tal técnica torna-se, portanto, somente um instrumento capaz de mensurar se os objetivos fixados pelo professor foram alcançados, não orientando os alunos quanto as suas falhas, correções e ganhos. Entretanto, a avaliação da aprendizagem não é simplesmente o confronto entre as metas estabelecidas e os resultados obtidos, uma vez que esse mecanismo possui implicações sociais. A avaliação também cria uma hierarquia de excelências entre os alunos no seio da escola, de modo a distinguir o binômio entre os bons/competentes/aptos e os incompetentes/ fracassados/inaptos, auxiliando no efeito social de manter a hierarquia na sociedade burguesa.

A partir disso, surge a problemática do presente texto: será que esta forma de avaliar, baseada em exames, além de classificar os alunos em sala de aula, não promove um efeito social, que é criar uma hierarquia para consolidar a sociedade atual?

Partindo dessa premissa, em um primeiro momento, define-se o conceito do processo de ensino e aprendizagem, apresentando a avaliação como mecanismo legitimador da pedagogia tradicional; no momento seguinte, mergulha-se no conceito da avaliação enquanto exame com seus caracteres pontuais, excludentes e seletivos, para, no último, apresentar o marco teórico do autor francês Philippe Perrenoud com as hierarquias de excelências escolares.

Notadamente, o presente texto afasta a compreensão de Pedro Demo (1999) sobre a avaliação como ato intrínseco à classificação e exclusão, próprio, inclusive, do contexto social em que todos estão inseridos, de modo a concebê-la como um paradigma de exame com abordagens classificatórias e excludentes. Isso porque, ao dar notas a um aluno, há uma mensagem subliminar para criar posições, já que haverá um grupo que será o modelo, isto é, o padrão a ser seguido pelos demais e, abaixo, os reprovados que, estigmatizados pela incompetência, serão excluídos.

A exclusão, no entanto, conforme será discutida mais adiante, não fica adstrita ao âmago escolar, tendo em vista que socialmente esse ciclo de submissão de um grupo pelo outro é também observado na sociedade burguesa (sociedade dividida em classes, na qual uma classe é subordinada e explorada por outra).

A avaliação na perspectiva de exame auxilia na compreensão da classificação, seleção e exclusão dos alunos dentro da sala de aula, bem 
como, para além dos muros escolares, contribui para a divisão da sociedade, consolidando uma hierarquia social.

\section{Processo de ensino e aprendizagem}

O entendimento do fenômeno educativo, segundo Santos (2005), perpassa pelo binômio tradicional do ensinar versus aprender como ações disjuntivas, classificadas, respectivamente, em atividade (ensinar) e tarefa (aprender) que dependem de crenças e valores dominantes da sociedade e da cultura de determinado momento histórico.

Nesse âmbito, o processo de ensino e aprendizagem mostra-se "humano, histórico e multidimensional" (MIZUKAMI, 1986, p. 1) na medida em que a dimensão sociopolítica interfere na construção de diferentes abordagens educacionais que incluem a tradicional, a comportamentalista, a humanista, a cognitivista e a sociocultural, cada qual com seus princípios e componentes sobre o comportamento da escola e do aluno, professor e método.

Segundo Bressan (2012), há inúmeras concepções de ensino e aprendizagem, todas com perfis representando os processos históricos evolutivos da humanidade, perfectibilizadas em teses que serviram como debate para atender as questões emergentes do seu tempo.

Partindo desse pressuposto, o modelo brasileiro de ensino e aprendizagem está historicamente arraigado à pedagogia católica, com os padres jesuítas (Manual Ratio Studiorum, 1599) e à pedagogia protestante (com o bispo John Amós Comênio), marcadas pela disciplina, pela técnica da prelação do conteúdo pelo professor, pelo modo de retirar dúvidas, de aplicar exercícios, e, ao final, a demonstração pelos alunos da apropriação do conteúdo (ANASTASIOU; ALVES, 2003).

Essa forma "catequética e unificadora" (MIZUKAMI, 1986, p. 17), baseada no ensino pela transmissão dos conhecimentos por parte do professor e pelo registro e apreensão do conteúdo e das fórmulas pelo aluno, dá ensejo àquilo que Bordenave (1984, p. 41) expressou como "pedagogia da transmissão", que significa a valorização dos conteúdos por alunos que estão na condição de passivos e futuros cidadãos obedientes.

$\mathrm{O}$ ensino tradicional, intrínseco ao entendimento filosófico do homem como um ser humano "acabado/pronto", tem como primado o conhecimento como objeto, do qual o aluno deve ser simples depositário e a escola, o local propício para sua transmissão (SANTOS, 2005, p. 21), ficando excluídas as historicidades com a criação de um estudo fragmentado.

O método está baseado no conhecimento que dispõe o mestre em caráter de autoridade, já que é ele quem detém o poder do conhecimento, cabendo transmiti-lo aos alunos em posição vertical, conforme disserta Libâneo (1994, p. 55):

Os conteúdos, os procedimentos didáticos, a relação professor-aluno não têm qualquer relação com o cotidiano do aluno e muito menos com as realidades sociais. É a predominância da palavra do professor, das regras impostas, do cultivo exclusivamente intelectual.

Nesse quadrante, a compreensão do que seja ensinar fica limitada à seleção e à elaboração dos conteúdos que devem ser transmitidos pelo professor, distanciando-se do real significado do verbo ensinar, que do latim se traduz como insignare: marcar com um sinal que deveria ser de busca e despertar para o conhecimento (ANASTASIOU; ALVES, 2003).

Conforme enfatiza Piaget (1980 apud BRESSAN, 2012, p. 112), a educação deve ter como principal objetivo "criar pessoas capazes de fazer coisas novas e não simplesmente repetir o que as outras gerações fizeram", pois a educação, ainda que represente uma violência simbólica (BOURDIEU, 1978), é capaz de fazer 
a "revolução" para executar um projeto de transformação social, em consonância com a visão de Freire (2011 apud Bressan, 2012, p. 112), ao destacar que "se a educação sozinha não transforma a sociedade, sem ela tampouco a sociedade muda".

Além disso, por meio dessa relação entre o sujeito e o conhecimento, a cultura tradicional não demonstra existir diferenças entre receber a informação ou reorganizar as ideias na construção do conhecimento, uma vez que ao aluno somente é possível realizar uma conduta passiva.

Entretanto, como bem alerta Anastasiou (2003, p. 14), existe uma diferença entre "aprender e apreender", pois o primeiro verbo significa receber a informação e reter na memória, ao passo que o segundo expressa compreender e assimilar mentalmente, formando o seu próprio conhecimento.

A simples diferença de significados entre os mencionados verbos cristaliza-se numa crítica ao papel que se propõe o professor na meta que estabelece para ensinar bem como da sua compreensão quanto à tarefa do aluno em sala de aula, uma vez que se o entendimento dele for apenas apropriação de conhecimento não há necessidade de superar o aprender. Diante disso, consoante ensina Anastasiou (2003), há a necessidade de inverter esse paradigma tradicional de modo que o aluno adote uma postura constante e consciente e o professor uma atuação de estratégia definida como facilitador do conhecimento.

Assim, embora não exista uma resposta correta para se determinar a melhor escolha de um programa de ensino, o importante é demonstrar que tal escolha seja feita de forma consciente e que leve em consideração quem é o aluno e qual é o contexto da instituição em que o professor está vinculado (GHIRARDI, 2012).

No entanto, ainda que seja necessário superar a lógica do ensino tradicional, baseado na exposição de conteúdo e na memorização por abordagens que conceba o ser humano em construção e movimento, dinamicamente sendo construído para compreender as matérias, o fato é que o método tradicional é o que prevalece no sistema brasileiro. E, a partir dessa propedêutica do processo de ensino e aprendizagem pelo método tradicional, surge intimamente a necessidade de se constatar socialmente se os resultados da transmissão do conhecimento foram obtidos dentro do processo. Nesse sentido, a avaliação surge para constatar se um específico aluno está apto ou não a prosseguir às demais fases escolares, conforme explica Sakamoto (2008, p. 2):

\begin{abstract}
A avaliação é um conceito que designa o processo de confronto entre as metas estabelecidas e os resultados obtidos. A prática da avaliação permite verificar o grau de consecução dos objetivos, através da comparação das metas com os resultados, ajuda a detectar as falhas e incorreções no processo de ensino e aprendizagem e facilita a distribuição dos resultados escolares dos alunos de acordo com uma escala previamente definida.
\end{abstract}

Nessa senda, a relação pedagógica depende de um instrumento legitimador das suas atividades, isto é, de um mecanismo que ateste o conhecimento transmitido pelo professor e que corrobore com a ideia de que o aluno sintetizou a matéria.

Nesse âmbito, reproduzindo o modelo sistematizado dos séculos XVI e XVII que se consolidou com a emergência da sociedade burguesa, a avaliação assume o papel de agente confirmador da pedagogia tradicional, capaz de aferir qual sujeito passivo adquiriu o conhecimento e detém condições de continuar as próximas fases (ROMANOWSKI, 2003). Assim, em um contexto em que o professor apresenta os conteúdos e os alunos os memorizam, a avaliação assume a função de exame, uma vez que valoriza o processo cognitivo e a verificação dos resultados por meio de provas nas quais os alunos apenas 
reproduzem um conhecimento.

O contexto tradicional do ensino, necessitado de um mecanismo que constatasse o conteúdo repassado pelo professor, contribuiu para o surgimento da avaliação como forma de certificação, maneira que atualmente permanece posta como uma metodologia pautada apenas em exames e utilizada somente com o seu caráter de controle.

Portanto, a avaliação perfaz-se como o instrumento justificador da aptidão do aluno em ultrapassar ou não uma fase escolar, assumindo, por vezes, para além dos muros escolares, o papel hierarquizado no processo de socialização, conforme será discutido nos próximos tópicos do presente texto.

\section{Caracterização da avaliação como exame}

Conforme demonstrado no tópico anterior, a prática da avaliação no processo de ensino e aprendizagem tradicional designa um mecanismo entre as metas estabelecidas pelo professor e os resultados obtidos e demonstrados por seus alunos.

Dessa forma, o termo avaliação encontrase relacionado à questão da eficiência dos resultados e surgiu no ano de 1930, pelo educador norte americano Ralph Tyler, que se dedicou à questão do ensino eficiente para "cotejar cada instrumento de avaliação que for proposto com os objetivos que se tem em mira" (TYLER, 1981, p. 166).

Nessa senda, a mencionada visão reduz o âmbito da avaliação ao domínio do conteúdo transmitido pelo professor e a verificação dos resultados, deixando fora desse sistema outras funções que a avaliação exerce no ensino. Isso porque a avaliação atravessa o ato de planejar, executar e contribui em todo o percurso da ação planificada, pois se faz presente não só na identificação da perspectiva político social, como também na seleção de meios alternativos e na execução do projeto como "uma ferramenta da qual o ser humano não se livra. Ela faz parte de seu modo de agir e, por isso, é necessário que seja usada da melhor forma possível" (LUCKESI, 2002, p. 118). Em consonância, Sordi (2002 apud BACKES, 2015, p. 8) expressa que uma avaliação

espelha um juízo de valor, uma dada concepção de mundo e de educação, e por isso vem impregnada de um olhar absolutamente intencional que revela quem é o educador, quando interpreta os eventos.

A avaliação, não como exame, conforme está pautada atualmente e será discutida aqui, mas na sua amplitude, tem por objetivo auxiliar o educando no seu crescimento e integração como sujeito existencial e cidadão(SAKAMOTO, 2008).

A avaliação diagnóstica permite a tomada da decisão mais adequada, tendo em vista o desenvolvimento e o auxílio externo, assim, para o processo não ser autoritário e conservador, a avaliação

tem a tarefa de ser diagnóstica, ou seja, deverá ser o instrumento dialético do avanço, terá de ser o instrumento da identificação de novos rumos. (LUCKESI, 2002, p. 43).

Dessa forma, ressalta-se que a avaliação como mecanismo dinâmico, construtivo e vinculado a uma perspectiva de processo, não se encaixa no método tradicional, precisando de uma pedagogia que conceba o ser humano em construção, em movimento, dinamicamente sendo construído. Assim, é necessário transpor para outra direção, com uma pedagogia construtiva, não necessariamente construtivista, no sentido de não tomar o ser humano como pronto, mas sim em movimento (BACKES, 2015).

Logo, admite-se a avaliação como um ato que subsidia um resultado mais satisfatório do que está ocorrendo, contudo só será possível alcançá-lo se a escola tiver o entendimento de que é possível, e, isto está relacionado com 
movimento.

Nessa senda, em um processo pedagógico adequado, a caracterização da avaliação pressupõe, segundo Rodrigues (2012, p. 260), três funções concomitantes, quais sejam: didático-pedagógica, diagnóstica e controle, que significam, respectivamente:

A função didático-pedagógica da avaliação é aquela que ela exerce dentro do processo de ensino-aprendizagem, como elemento que contribui para aquisição de conteúdos, o desenvolvimento de habilidades e competências, e a produção de conhecimento. Avaliar gradativamente os envolvidos no processo de ensino aprendizagem para verificar se esse processo está cumprindo seus objetivos, permitindo dessa forma a atualização gradativa do planejamento inicial e a correção dos erros e equívocos verificados, é utilizá-la como instrumento diagnóstico. A utilização da avaliação como instrumento de controle é a mais conhecida. É quando ela é utilizada para estabelecer, dentro do processo, quem já adquiriu os conteúdos e desenvolveu as habilidades e competências de uma determinada etapa do processo ensino-aprendizado, estando então apto a prosseguir e passar para etapa seguinte.

Entretanto, como há um sistema de avaliação, histórico escolar e dia específico para avaliação, os professores se equivocam ao dizer que estão avaliando os alunos, todavia, genericamente, o que praticam são exames, uma vez que utilizam o instrumento somente com a função de controle, deixando as medidas didático-pedagógicas e a diagnóstica excluídas do total do processo pedagógico.

Segundo a análise histórica de Luckesi (2002, p. 38), a ação de acompanhamento da avaliação da aprendizagem do aluno denominase "avaliação da aprendizagem escolar", mas na prática o que se constata, nas escolas brasileiras, desdeaeducaçãobásica,éarealizaçãodeexames.

Convém mencionar que os exames são dotados de atributos como: pontualidade (tem como fundamento um entendimento filosófico do ser humano como pronto, e, por isso, a ideia de pontual), seleção (coloca fora do sistema social uma parcela ou grande parte da população, ao selecionar os bons ele automaticamente exclui os supostamente incompetentes) e exclusão (rotula entre os aprovados - competentes/bons - e os reprovados - incompetentes/fracassados - por meio de contabilização dos resultados) (LUCKESI, 2002).

Para Luckesi tem sentido utilizar os exames como instrumentos classificatórios em situações específicas, como concursos ou quando é exigida a certificação de conhecimentos pontuais, mas na sala de aula a avaliação é um recurso para diagnosticar, acompanhar e reorientar a aprendizagem e não se deve utilizá-la para proceder à classificação de alunos (LUCKESI, 2002 apud BACKES, 2015).

Contudo, o processo pedagógico permanece pautado na valorização dos aspectos cognitivos com ênfase na memorização e a verificação dos resultados ocorre por meio de provas orais ou escritas nas quais os alunos devem reproduzir exatamente aquilo que lhe foi ensinado.

Devido a isso, retira-se da avaliação o seu papel pedagógico (contribuir para aquisição do conteúdo) e diagnóstico (verificar se esse processo está cumprindo seus objetivos) para que, de forma gradativa e com planejamento, produza-se a correção dos erros e equívocos verificados, reduzindo o instrumento a uma medida verificada pelo método da prova:

a avaliação não é uma medida pelo simples fato de que o avaliador não é um instrumento, e porque o que é avaliado não é um objeto no sentido imediato do termo. Todos os professores avaliadores deveriam, portanto, ter compreendido definitivamente que a "nota verdadeira" quase não tem sentido. (HADJI, 2001 apud CHUERIRI, 2008, p. 56).

O ato de avaliar, consequência, como já mencionado, da tradição pelos padres jesuítas 
(séc. XVI) e pela pedagogia protestante (fim do séc. XVI e primeira metade do séc. XVIII), consolidou-se apenas como exames, ou seja, no sistema educacional tradicional, no qual o professor reproduz o modelo de exames distanciando-se da avaliação como um

ato dinâmico em que aluno e professor assumem o papel, de modo co-participativo, através da implementação do diálogo e da interação. (SAKAMOTO, 2008, p. 1).

A avaliação se torna, portanto, apenas um instrumento de exame para mensurar se os objetivos outrora fixados pelo professor foram alcançados e controlar a aptidão dos alunos, despida da sua real essência dinâmica e inclusiva.

Assim, partindo da caracterização da avaliação como instrumento de controle, isto é, como representativa de exames que são por sua natureza, pontuais, seletivos e excludentes, a avaliação produz um efeito perverso no interior da sala de aula: exclui e seleciona os alunos.

Avaliar para classificar ou para regular é uma das concepções mais tradicionais acerca da avaliação escolar. Os alunos são comparados a partir de uma norma, de um padrão determinado pelo professor. Ela tem a função tradicional de certificação, a qual fornece poucas informações sobre o conhecimento adquirido e o domínio atingido sobre determinado assunto. Neste tipo de avaliação, o foco está naquilo que está programado para ser avaliado e não no desenvolvimento real do aluno. (BACKES, 2015, p. 7).

Ocorre que a concepção que propõe a classificação dos alunos dentro de parâmetros, nos quais são agrupados pelo dualismo entre os bons/maus, fortes/fracos, competentes/ incompetentes, merecedores de prêmio/punição pelo fracasso, contribui para marginalização dos alunos, ou seja, justifica a exclusão (BACKES, 2015, p. 9).
Portanto, a manutenção da avaliação como um julgamento seletivo sustenta-se como forma de classificação - por meio de provas e notas - quanto ao desempenho do educando sobre determinado conteúdo, classificando-o em aprovado e reprovado, para escaloná-lo, por fim, dentro do sistema de ensino (utilizando nota de 0 a 10) e conduzi-lo não apenas a uma hierarquia escolar, mas a uma exclusão cimentada na sociedade dividida em classes (elitista), conforme será analisado no próximo tópico.

\section{Avaliação e seu efeito social}

O processo avaliativo, como representante de um dos instrumentos de violência simbólica na educação, cria um estigma ao aluno que

não adquiriu no prazo previsto os novos conhecimentos e as novas competências que a instituição, conforme o programa, previa que adquirisse, como sendo um aluno fracassado. (ISAMBERT-JAMATI, 1984 apud PERRENOUD, 1999, p. 56).

Nesse sentido, a avaliação se inscreve em uma relação social, uma transação mais ou menos tensa entre, de um lado, o professor e, de outro, o aluno e sua família, na qual nem sempre há negociação explícita (PERRENOUD, 1999), porém há êxito ou fracasso ${ }^{2}$. Embora êxito e fracasso escolares não sejam conceitos científicos, denotam extrema polissemia, que acarreta algumas implicações:

A primeira delas diz que o mesmo é atribuído ao aluno "fracassado", aquele que não progrediu praticamente nada durante seus anos escolares, nem no âmbito de seus conhecimentos, nem do seu desenvolvimento pessoal e social. Uma segunda ideia diz que o problema central reside no fato de que o termo qualifica uma imagem negativa

2. Para Charlot (2005), o fracasso escolar, tratado como um monstro escondido no fundo da sala de aula, não existe, pois o que há são alunos que apresentam dificuldades para aprender. 
do aluno, afetando sua autoestima e sua confiança. Por fim, uma terceira ideia centra no aluno o problema do fracasso e distancia a responsabilidade de outros agentes e instituições, como as condições sociais, a família, o sistema educacional ou a própria escola. (MARCHESI; PÉREZ, 2004, p. 17).

Fato é que ambas as terminologias estão acostadas no cenário escolar, de modo que a prática de avaliação, ao criar modalidades de hierarquias de excelência escolar e, depois, julgamentos de êxito ou de fracasso, conduz não apenas a uma hierarquia de excelência escolar, como também, a diversas implicações sociais.

Segundo Perrenoud (1999, p. 185), as hierarquias de excelência escolar, das mais formais às mais intuitivas, são apenas representações. Entretanto, não são quaisquer representações: "elas fazem lei, passam por uma imagem legítima de desigualdades bem reais de conhecimentos ou de competências". Isso explica porque toda hierarquia retira sua legitimidade do desconhecimento relativo da arbitrariedade de seu modo de criação e, por isso

teriam menos peso, durante a escolaridade e depois dela, se os principais interessados duvidassem da realidade das desigualdades que elas pretendem "refletir", nem mais, nem menos. (PERRENOUD, 1999, p. 185).

Na prática, a avaliação da aprendizagem baseada em exames classifica os alunos em sala de aula e, a partir dessa distinção entre os supostamente competentes e os incompetentes, isto é, os com excelência escolar e os despidos de tal atributo, decorre a problemática de que essa técnica além de causar diferenciação interna, também promove um efeito social, que é criar uma hierarquia social para consolidar a sociedade atual.

Construindo seu próprio conceito, Demo (1999, p. 21), opondo-se à posição romântica à moda de Luckesi, disserta que a avaliação é instrumento intrínseco ao próprio contexto social, pois é "inviável avaliar sem dispor de escala de contraste", isto é, comparar, classificar e escalonar são práticas sociais reais, e, negar isto, é desconhecer a realidade social a qual se está inserido. E o autor vai além:

Desse modo, será possível observar que por trás de certas mitologias da avaliação paira visão ingênua da realidade social, como se fosse viável, por exemplo, acabar com as desigualdades sociais ou creditando todos os problemas ao capitalismo ou neoliberalismo. É impraticável escamotear a visível ligação entre avaliação e desigualdade social, bem como imaginar que, não avaliando ou fazendo de conta que se avalia, estaríamos combatendo a desigualdade. É sempre possível decantar na pedagogia que os alunos não deveriam ser comparados entre si, porque cada um tem seu ritmo próprio, mas na prática, o fato dos alunos estarem juntos numa sala é o bastante para os escalonar, o que transforma simples diferenças em autênticas desigualdades. (DEMO, 1999, p. 10).

Dessa forma, a avaliação não cria a classificação, uma vez que a sua essência já é classificatória, pois a própria ideia de aprendizagem contém esse

incômodo comparativo, quando, ao desenvolver as potencialidades de cada um, admitimos que são diferentes, o que já é mais que suficiente para, no contexto social, descambar em dinâmicas desiguais. (DEMO, 1999, p. 11).

Além disso, toda a sociedade, ao realizar

seu processo de socialização, através do qual padroniza os comportamentos, papéis, normas e valores, classificam as pessoas e grupos, revelando tendência funcional de preferir o cidadão medíocre ao criativo. (DEMO, 1999, p. 11).

Na mesma direção, Bourdieu (1978, p. 33) revela que a escola se conformou com as desigualdades do êxito por tanto tempo quanto 
elas pareciam na ordem das coisas, pois era importante que

o ensino fosse corretamente distribuído e que os alunos trabalhassem, mas a pedagogia não pretendia nenhum milagre, ela não podia senão revelar as desigualdades das aptidões.

Entretanto, ainda que o conceito de avaliação seja por sua natureza classificatória e excludente, o fato é que essa trajetória opera efeitos sociais, tendo em vista que privilegia

um modo de estar em aula e no mundo, valoriza formas e normas de excelência, define um aluno modelo aplicado e dócil para uns, imaginativo e autônomo para outros. (PERRENOUD, 1999, p. 9).

Desse modo, a organização social apresenta relações de subordinação em graus sucessivos e divisão em classes sociais, enquanto a prática da avaliação do professor, ao classificar e distribuir os alunos em grupos, determina uma hierarquia social.

Entende Perrenoud (1999, p. 9) que a prática da avaliação classifica e distribui as classes ou grupos, pois "inflama necessariamente as paixões, já que estigmatiza a ignorância de alguns para melhor celebrar a excelência de outros" e, com isso, consolida a divisão de classes na sociedade.

Criam-se, assim, posições: de um lado, em grau elevado há um grupo de alunos que serão os modelos (padrão a ser seguidos pelos demais) e, abaixo, os reprovados, que estigmatizados pela incompetência serão excluídos socialmente. Por isso a avaliação é um processo que opera efeitos para além dos muros da escola, uma vez que:

Avaliar é - cedo ou tarde - criar hierarquias de excelências, em função das quais se decidirão a progressão no curso seguido, a seleção no início secundário, a orientação para diversos tipos de estudos, a certificação antes da entrada no mercado de trabalho e, frequentemente a contratação. Essas hierarquias têm em comum mais informar sobre a posição de um aluno, em um grupo ou sua distância relativa à norma de excelência, do que sobre o conteúdo de seus conhecimentos e competências. Isto é, uma hierarquia de excelência jamais é o puro e simples reflexo da realidade das variações. Elas existem realmente, dar-lhes uma imagem pública. (PERRENOUD, 1999, p. 12-13).

A avaliação no modelo tradicional de exames não é isenta e negar a "marca classificatória da avaliação implica desconhecer o contexto social da escola, mais do que se contrapor ao autoritarismo" (DEMO, 1999, p. 17). Ela cria hierarquias de excelências, uma vez que os alunos são comparados e depois classificados em virtude de uma norma/modelo/ padrão excelente, definido pelo professor.

Disso resultam, segundo o autor Perrenoud (1999), duas lógicas do critério de avaliação: a primeira como promoção humana e a segunda como missão social para os professores tentarem não mais perenizar a hierarquia social.

Portanto, da função seletiva e excludente no interior da sala de aula, proporcionada pela avaliação como exame, é que se reproduz e sustenta o modelo da sociedade burguesa, que exclui e marginaliza grande parte de seus membros.

\section{Considerações finais}

O processo de ensino e aprendizagem está baseado na formação do aluno como sujeito passivo das informações prestadas pelo professor, no qual a avaliação assume papel de referendar a transmissão e a recepção do conhecimento dentro desse modelo tradicional.

A partir do modelo tradicional do processo de ensino e aprendizagem, baseado na técnica da prelação do conteúdo pelo professor (agente ativo que detém o conhecimento) e a demonstração pelos alunos da apropriação do conteúdo (agente passivo que apenas recepciona as informações), a avaliação torna- 
se o instrumento legitimador da mencionada prática.

Pautada somente em exames, a avaliação do processo de ensino e aprendizagem fica reduzida como meio de atestar e controlar quais alunos estão aptos a prosseguir às demais fases, destoando das suas funções primordiais de cunho pedagógico e diagnóstico.

Em que pese à avaliação ter sido concebida como um ato que pretendia um resultado mais satisfatório do que está ocorrendo agora, fato é que esse resultado só poderá advir do entendimento do ser humano enquanto ciclo em movimento/construção. No entanto, a avaliação passou a ser confundida com o ato de examinar, que possui um entendimento filosófico do ser humano como pronto, e, por isso, pontual, em que ela supostamente seleciona os melhores e exclui os fracassados do sistema escolar.

Dessa forma, ao enxergar na avaliação o mecanismo de examinar os alunos que possuem aptidão para transpor as demais etapas do ensino, perdeu-se aquele mecanismo de diagnosticar as falhas, corrigir os erros e melhorar a aprendizagem, ficando ela reduzida ao controle da capacidade das metas e resultados dos alunos.
Atualmente, o diagnóstico da avaliação representa a criação da classificação de grupos no seio escolar, na medida em que "acima" temos o grupo dos competentes e "abaixo" os incompetentes que deverão se submeter àquele grupo. A consequência desse ato de avaliar, confundido com exame, está, portanto na classificação, seleção e exclusão dos alunos dentro da sala de aula, porém opera efeitos para além dos muros escolares, como a estratificação da sociedade, isto é, a avaliação é um mecanismo que promove uma hierarquia social, consolidando uma sociedade de classes.

Ocorre que esse efeito de exclusão, seleção e sujeição de um grupo fracassado pelo outro superior, prolifera-se para além dos muros da hierarquia escolar, pois é capaz de sustentar a divisão de classes da sociedade burguesa.

Portanto, a forma como a avaliação do processo de ensino e aprendizagem está posta atualmente no processo pedagógico como um instrumento de controle, baseado em exames, contribui para consolidar não apenas uma classificação dos alunos no interior da escola, mas também um efeito social de hierarquia, consolidando-se da hierarquia escolar à social.

\section{Referências}

ANASTASIOU, L. das G. C.; ALVES, L. P. Processos de ensinagem na Universidade: pressupostos para estratégias de trabalho em aula. Joinville: Univille, 2003.

BACKES, D. D. B. Avaliação do processo ensino aprendizagem: conceitos e concepções. Disponível em: <http://www.nre.seed.pr.gov.br/cascavel/arquivos/File/Equipe\%20Pedagogica/ producao_dorimar.pdf $>$. Acesso em: 1 jun. 2015.

BORDENAVE, J. E. D. A opção pedagógica pode ter consequências individuais e sociais importantes. Revista de Educação AEC, São Paulo, n. 54, p. 41-50, 1984.

BOURDIEU, P. A reprodução: elementos para uma teoria do sistema de ensino. Lisboa: Editorial Vega, 1978.

BRESSAN, L. L.; MENDES, M. O. O cinema como ferramenta no ensino da argumentação. Ponto de Vista Jurídico, Caçador, v. 1, n. 1, p. 106-116, 2012. Disponível em: <http://www. periodicosuniarp.com.br/juridico/article/view/51/76>. Acesso em: 1 jun. 2015 
CHARLOT, B. Formação de professores: a pesquisa e a política educacional. In: PIMENTA, S. G.; GHEDIN, E. (Orgs.). Professor reflexivo no Brasil: gênese e crítica de um conceito. São Paulo: Cortez, 2005. p. 89-108.

CHUERIRI, S. F. Concepções sobre avaliação escolar. Estudos em avaliação educacional, São Paulo, v.19, n. 39, p. 49-64, jan./abril, 2008.

DEMO, P. Mitologias da avaliação: de como ignorar, em vez de enfrentar problemas. Campinas: Autores Associados, 1999.

GHIRARDI, J. G. O instante do encontro: questões fundamentais para o ensino jurídico. São Paulo: Fundação Getúlio Vargas, 2012.

LIBÂNEO, J. C. Didática. São Paulo: Cortez, 1994.

LUCKESI, C. C. Avaliação da aprendizagem escolar: estudos e proposições. 14. ed. São Paulo: Cortez, 2002.

MARCHESI, A.; PÉREZ, E. M. A Compreensão do Fracasso Escolar. In: MARCHESI, A.; GIL, C. H. Fracasso escolar: uma perspectiva multicultural. Porto Alegre: Artmed, 2004. p. 17-33.

MIZUKAMI, M. da G. N. Ensino: as abordagens do processo. São Paulo: EPU, 1986.

PERRENOUD, P. Avaliação: da excelência à regulação da aprendizagem - entre duas lógicas. Porto Alegre: Artmed, 1999.

RODRIGUES, H. W. Avaliação da aprendizagem nos cursos de Direito: novas e velhas possibilidades. In: RODRIGUES, H. W.; ARRUDA JÚNIOR, E. L. de (Org.). Educação jurídica: temas contemporâneos. Florianópolis: Fundação Boiteux, 2012. p. 255-278. Disponível em: <http://funjab.ufsc.br/wp/?page_id=1819>. Acesso em: 12 abr. 2015.

ROMANOWSKI, J. P. Avaliação formativa no ensino superior: que resistências manifestam os professores e os alunos. In: ANASTASIOU, L. das G. C.; ALVES, L. P. Processos de ensinagem na Universidade: pressupostos para estratégias de trabalho em aula. Joinville-: Univille, 2003.

SAKAMOTO, B. A. M. A avaliação em questão: Perrenoud e Luckesi. 2008. Disponível em: < http:// Itc-ead.nutes.ufrj.br/constructore/objetos/Artigo\%20sakamoto.pdf>. Acesso em: 12 abr. 2015.

SANTOS, R. V. dos. Abordagens do processo de ensino e aprendizagem. Integração, n. 40, p. 1931, jan./maio 2005. Disponível em: <ftp://www.usjt.br/pub/revint/19_40.pdf >. Acesso em: 12 abr. 2015.

TYLER, R. Princípios básico de currículo e ensino. Porto Alegre: Globo, 1981.

Submetido em 22 de junho de 2015.

Aprovado em 22 de julho de 2015. 